\title{
Social spatiality: some rudimentary thoughts on the epistemology of Benno Werlen
}

\author{
U. Strohmayer \\ School of Geography \& Archaeology, National University of Ireland, Galway, Ireland \\ Correspondence to: U. Strohmayer (ulf.strohmayer@nuigalway.ie)
}

Werlen, B.: Gesellschaftliche Räumlichkeit 1: Orte der Geographie, Stuttgart, Franz Steiner 2010a.

Werlen, B.: Gesellschaftliche Räumlichkeit 2: Konstruktion geographischer Wirklichkeiten, Stuttgart, Franz Steiner $2010 b$.

Benno Werlen requires no introduction to readers of $\mathrm{Ge}$ ographica Helvetica: arguably the most internationally resonating of names amongst Swiss human geographers writing today, the Jena-based social geographer has not only published prolifically over the course of the last three decades (with arguably one of his first position-embracing papers published in the pages of this journal; see Werlen, 1986), he has furthermore left a considerable imprint on the next generation of theoretically aware human geographers expressing their ideas through the medium of German today. Significantly, this influence extends beyond the often ritualistic invocation of a name and makes itself felt in the tacit acceptance of basic premises, academic tactics and research programmes. Since 2005, much of the ensuing research has found a home in the Sozialgeographische Bibliothek, a series of books edited by Werlen for the Franz Steiner Verlag, which both expresses and solidifies the grasp of his influence within German-speaking human geography today. And while it would be premature to speak of pilgrimages that mount the lofty heights towards Werlen's apartment in the centre of one of Germany's oldest university towns, I gladly admit to being no stranger to Werlen's famous hospitality in Jena myself. Thankfully though, the gregariousness encountered when meeting Benno Werlen is matched by an ever-present invitation to discuss, debate and challenge whichever idea is accorded centre stage on the day. The present contribution to the Interfaces section of Geographica Helvetica was written as an homage to this invitation.

A broad - and admittedly subjective - sketch will have to suffice to contextualise the nature and importance of
Werlen's contribution to the discursive and empirical landscape of German-speaking human geography. Since many of Werlen's individual works have been reviewed in Geographica Helvetica and elsewhere on a regular basis, I may be permitted a more general summary and tentative critique today, an outline that arguably should start with the initial opening of German-speaking geography towards a more open and visible embrace of theoretically motivated thought-andpractice in Dietrich Bartels' now canonical Habilitationsschrift of 1967 (published in 1968); surveying the scene today, any observer will note and perhaps celebrate a considerably more pluralistic landscape of theoretically motivated empirical research emanating from geographical Lehrstühle in Germany, Switzerland and Austria following that other momentous expression of " 1968 ". Werlen's contribution to the emergence and shaping of this pluralism is considerable and is perhaps less motivated by the direct link to Bartels Werlen was Bartels' Assistent in Kiel three years before Bartels' untimely death in 1983; his critical homage to Bartels is contained of Volume 1 of Gesellschaftliche Räumlichkeit (pp. 130-146; see also p. 288) - than by Werlen's cautious engagement with the linguistic (soon to be re-christened "spatial" or "cultural") turn then nascent within Englishspeaking human geography. We shall return to Werlen's engagement with these (twists and) turns soon; for now, suffice it to say that it was arguably Werlen's openness towards non-German influences - which itself was perhaps motivated and facilitated by linguistic competences acquired through an early immersion into the Swiss educational system - that initially made his voice distinct within the context of German-speaking human geography. This is an important point to stress given the fruitful engagement with social theory by a number of human geographers following in the wake of Bartels' initial gesture; it is also important in the context of an unfortunate absence of a sustained engagement with Werlen's ideas outside of German-speaking geographical networks, the translation of his doctoral thesis into 
English notwithstanding (Werlen, 1993). This asymmetry in reception and engagement across national borders underlies and informs a ruinous continuity within human geographical discourse and practice (see Best, 2009; Minca, 2013).

At the same time, the comprehensive nature of Werlen's published oeuvre equally singles it out in the context of an increasingly dominant Angle-Saxon human geography. Where the latter is often characterised by both a short response time to newly emerging trends and a pronounced antipathy to historicization, Werlen carefully contextualises his work within a clearly articulated and legible history of ideas, all the while refusing to become a victim to fashion. So, then, what of this oeuvre and its contribution to theoretical discourse? Read against the prevailing intellectual currents of the past three decades, the latter displays all the trappings of a developed anachronism: while both post-modernism and poststructuralism united underneath the banner of anti-grand theory gestures (possibly the only banner common to both), Werlen was swimming against the tide by thinking in a big and comprehensive manner. Ironically, such thinking would converge towards a point shared by many working in human geography today: the re-formulation of locally resonant, specific conditions for social constitution and reproduction what he consistently referred to as "regionalisation" in his published output. This particular point will bear closer inspection later, when we will have to contemplate the fact that for all the argumentative flurry and heat generated by and around Werlen's writings (captured partially in Meusburger, 1999 and the recently published volume of Erwägen Wissen Ethik, 2013), his position is ultimately rather compatible with key research practices that dominate within human geography today.

If Bartels' original intervention led to a vigorous embrace of empirical social scientific research programmes at many geography departments within Germany, Switzerland and Austria, Werlen's voice was recognisable not merely for its proposition of a complete and ambitious meta-theoretical body of work; rather, it is the overall gesture, as well as the specifics of his subject-centred, action-oriented theory that rendered Werlen's approach different from what could justifiably be called a mid-1980s orthodoxy. If the latter was characterised by a highly ritualised (and arguably fruitless) dichotomy between "quantitative" and "qualitative" epistemologies, Werlen forcefully insisted on the importance of those geographies that are produced within and through "everyday" settings and contexts. As chartered in the two volumes of (mostly) previously published essays spanning the period between 1983 and 2009 that somewhat belatedly prompted this short intervention (listed above), Werlen's theoretical explorations (Volume 1) and empirical exposition (Volume 2) of these everyday geographies is never less than interesting and always inspiring.

It is perhaps pertinent, by way of approaching the specific contribution recast in these two books, to briefly return to Werlen's critical and selective engagement with the various (linguistic, cultural, spatial) "turns" that characterised especially Anglo-Saxon human geography during the last three decades - and which increasingly have, at least since the turn of the millennium, shaped German-speaking academic geography. Werlen is correct in stressing that his interventions pre-date these "turns" (Werlen, 2013a, p. 33), but if we interpret both the "spatial" and the "cultural" turn to motivate and justify more nuanced theoretical and empirical engagements, interested as much in difference as in similarity and identity, his contribution can comfortably be located within the context of its own time. No surprise here - but worth mentioning, especially since the ensuing critique of singular identities and the engagement with complexity, hybridity or contradiction is arguably central to Werlen's thought and practice, if not to his adopted, and rather un-ambiguous, even dry, rhetoric. Furthermore, we collectively owe to these "turns" an all but universal acceptance of the idea of a "socially constructed" as opposed to a pre-given and thus accessible - reality within most human sciences. In geography, the result of such thinking has been a most thorough abandonment of the idea of (as well as epistemological practices associated with) space as a "container" within which structures and socially relevant activities arise or happen. In its stead, a majority of human geographers would today recognise the co-constitution of geographical space with those structures and activities that we can map as taking place there.

Again (and again not surprisingly), Werlen's writings sit comfortably within the broad consensus expressed above. What renders them unique, especially in the context of German-speaking human geography three decades ago, is the attempt to echo and geographically modify previous endeavours by the sociologists Anthony Giddens and - to a somewhat lesser extent - Pierre Bourdieu symmetrically in order to anchor socially relevant actions in broader epistemological frameworks (see especially chapter 2 in Werlen, 1995). Use of the term "symmetry" is anything but accidental in the present context: by insisting on an ever-present formative existence of both social structures and individual actions in processes of social reproduction, Werlen (following Giddens) initially negated the situated possibility of anything approaching an Althusserian "determination in the last instance". What this means in practice is that Werlen's approach appears not to allow for the possibility of determination at whatever scale: people, in his (as previously in Giddens') world, could always have acted differently and this retention of possibilities matters theoretically. It is this nondetermined engagement with social reality and the centrality accorded to human beings and their actions that is perhaps the most enduring (and for some, endearing) aspect associated with Benno Werlen's contribution to human geography - which is thus not coincidentally recast as "social" geography tout court. Crucially, Werlen's conceptualisation of human beings as social actors never lapses into a phenomenological pre-disposition of sorts; rather, he accords humans a degree of autonomy just sufficient enough to facilitate 
a meaningful interpretation of their motifs, thoughts, intentions, memories, experiences and desires in the results they create. While intentions and the like clearly exist, they do not become a focus of attention in their own right, but are conferred the status of a mere referent instead: they are, as Werlen astutely notes, always "thoughts of, memories of and phantasies of something" (2010a, p. 259). Not for Werlen, in other words, to engage with the currently tempting depths of either more-than-human or affect-inspired forms of geographic curiosity; actions, it seems, speak for themselves and either contribute to ongoing processes of social constitution and maintenance, or they don't; whatever embodiment can be attributed to these practices is thus important only insofar as it yields social consequences, insofar as it constitutes machen, rather than say dreaming.

The embeddedness of human action within a context (as an older form of human geography would have invited us to think) here gives way to the creation of space through human actions. Thus, to use one of many possible examples of such "space making" discussed in Volume 2 of Gesellschaftliche Räumlichkeit, the emergence and proliferation of geo-coded forms of information and associated uses (mobile phones, Google Earth, GPS-based car navigation systems, etc.; see 2010b, pp. 172-183) does not merely add to the possibility of representing reality but also - and arguably more importantly - alters the way societies are reproduced through different spatial configurations. But Werlen's appreciation and conceptualisation of space is anything but straightforward. Arguably, it is the complexities associated with his use of "space" that have accompanied and to some extent overshadowed his reception within human geography to this very day; on the one hand Werlen insists on the centrality of 'space' as a core, always already produced category, while on the other strategically refusing to accord "space" a distinct a priori existence and (thus) importance (he famously pondered the possibility and desirability of a "geography without space"; see Werlen, 2010b, pp. 17-36). If this latter refusal rendered his position as a geographer, rather than a social scientist, tentative in the eyes of many senior geographers working in the 1980s and 1990s, any fruitful engagement with this complexity may well require a shift in perspective that embraces Werlen the social scientist, only to rediscover the geographer he never ceased to be. As a "socially produced" space, Werlen's Raum clearly no longer aspires to be the oftencriticised "fetishized" space that attempted to translate social into spatial relations (see Collinge, 2005 for a rewarding engagement with these). In its stead, "Raum" has been transformed into something perhaps better referred to as "Räumlichkeit" (Werlen, 2013a, p. 8) or, in a more overtly epistemological context, as both a "medium" and an "instrument" (2013b, p. 46).

But accepting (as appears to be the consensus amongst many working in human geography today) that space and society do not exist in isolation from one another, but that they are mutually constitutive is one thing; meaningfully fill- ing the void left by whatever function "space" fulfilled in the epistemologies of old is another. In other words: as socially produced and thus fundamentally unstable, Werlen's "space" renders the dependency of society on some kind of (persistent or not) "materially given" or "nature" all but unthinkable; we may want to ask what kind of role such a space fulfils in the context of a theory that is explicitly about "(everyday) practice": if it is at once dependent upon such practices to be worthy of consideration and, at the same time, independent enough not to become one with whatever social configuration emerges, we may well wonder about its epistemological status.

Readers will have noticed a rhetorical shirt in the last paragraph. We should elaborate by stating that Werlen's Sozialgeographie thus occupies an interesting and, at the same time, impossible position. Its interest to geographers and other spatially minded scholars is clearly anchored in its claim to transcend the agency-structure divide that arguably plagued the responses formulated to the "spatial science" paradigm perceived to be dominant within Anglo-Saxon human geography in the later 1970s. What makes Werlen's "middle ground" additionally appealing is its emergence not in the form of a "lowest common denominator" kind of compromise, but as a fundamental functional intersection instead, positing "action" or "practice" as a necessary condition of possibility for both structural positivists and phenomenological humanists (see 2010a, pp. 288-292, where this argument is advanced with reference to the works of Karl Popper and Alfred Schütz; for a more concise rendition, see 2010b, pp. 37-49) ${ }^{1}$. Werlen furthermore posits the intersection developed above to form an "ontology of action" (2013, p. 38; see also 2010a, pp. 260-261), thus designating a fundamental truth, a condition of possibility, necessarily common to any human geography. The question however remains: even if this were to be the case, how can a social geography access or represent or examine this state of affairs? In other words: what would be the epistemological correlate to Werlen's central contention? Werlen's implied answer renders science (or social geography) part of the very process it aims to analyse: it, too, is a form of action or practice. This is consistent with his overall exposé, but has to rely on a specific capability whose existence it negates for the real world: for scientific practice to relate demonstrably to non-scientific (or "lay") practices (and after all, this is what "epistemology" is all about), it needs to be able to "arrest" or otherwise fix a potential flux of possibly related and (or) non-related practices at least momentarily. And the only way to accomplish this is by re-introducing something functionally akin to the much-maligned "container" notion of space. In its absence - and purely arguing from an epistemological position

\footnotetext{
${ }^{1}$ There is no space here fully to explore the important differentiation between "Handeln" (individual "doing") and "Praxis" (a more collectively resonant "practice") in the medium of English (see Werlen, 2013b, p. 48).
} 
- Werlen's contention, while one the one hand purporting to incorporate a possible spectrum of geographical scales from the body up, cannot also occupy any single one of these positions fully, thus sharing a conundrum with many previous meta-theoretical propositions (for an earlier attempt to identify this difficulty in the work of Giddens, see Hannah and Strohmayer, 1991).

We should note as an aside that Werlen's recent plea for trans-disciplinary forms of research, knowledge production and, crucially, dissemination within society at large (Werlen, 2013b) is thus entirely consistent with his overall exposé: embedding scientific praxis within the confines of developing, rather than pre-existing, thematically emergent problematic makes sense and should allow individual and disciplinary expertise to contribute in a meaningful manner to scientific progress. It is thus all the more perplexing to see Werlen consistently accord minor importance at best to the normative writings of Jürgen Habermas, whose development of dialogical reason might be thought to yield key insights as to how best to conceptualise and organise epistemological practices that involve conceptually different worlds. We shall have to return to this absence soon in this short Interface contribution.

If thus the undeniable appeal of Werlen's writings arguably stems from the singular-level of compatibility achieved therein, from the fact that his theoretical propositions are capable of explaining virtually every possible social configuration, we may well want to ask if this degree of generality is not arguably purchased at the expense of alternative conceptualisation. However, this is not an adequate forum to fully develop such a line of inquiry. Key to such alternatives as the collection of critical engagements in Erwägen Wissen Ethik already mentioned makes abundantly clear - remains the anchorage afforded by "the human" bringing about action in the first place. Even if, following Werlen, we were to focus solely on the consequences of actions, rather than their motivational genesis, looking, as it were, backwards from actions towards human beings would see his approach blur the line between humans capable of and humans actually delivering social change. In Werlen, the focus is on the latter. But is it not the former, the potential for change, that is equally worthy of consideration? Werlen appears to hint in just this direction when implicitly differentiating between "Handlungsvollzügen" (or those actions that are actually executed) and "Handlungsfähigkeit" (the capacity for action; see 2013a, passim; 2013b, p. 41) but never contemplates - cannot contemplate - a scenario where the two would not coincide and be relatable. In other words, the quite real possibility that people as subjects do not have any power is a scenario that is largely absent from Werlen's thought. This is not simply to echo Peter Meusburger's earlier critique (1999) that a geography centred on "practices" runs the risk of rendering real existing structures invisible, but to insist also on the possibility of refusal, disinterest, passive or active resistance and alternative forms of "making geography" more general.
The rather abstract rendition of Werlen's ideas advanced to this point will finally serve to demonstrate the arguably "naked" (or "Kantian") character of his epistemology: not for him to embrace a normative dimension of any kind, be it in the form of an outright plea for "justice" or any other time-worn normative dimension, say through the invocation of a particular societal dynamic of the "biopolitical" or "governmental" kind. These absences render the resulting analyses often somewhat understated and bereft of an obvious punch-line; by the same token, they acquire an abstract clarity comparable perhaps to the one found in the writings of Niklas Luhmann. However, while this abstraction represents a recognised quality of Werlen's work, it also makes it difficult for him to incorporate the concrete materialities that partially constitute - in addition to people's interpretation of the conditions contributing to their being-in-the-world - everyday life. In other words, the limitations attached to any kind of non-materialist phenomenology equally apply to Werlen's oeuvre. As do limitations arising from his negation of normative elements arising from or otherwise attached to an action-based social theory: although "change" is arguably at the forefront of Werlen's knowledge-constitutive interests, his theory does not - again, cannot - engage with the kind of emancipatory potential sought (or identified) in human action: questions of legitimacy - to use a key term developed by Jürgen Habermas (1968) - are all but absent from his writings. Writing at a time when the direction change should take is again very much up for grabs in the public imagination, with nostalgia for more clear and bounded (if no less imagined) forms of identity gaining traction in many societies, the unashamedly pragmatic question must be asked as to what kind of social theory we require for times such as these and whether a refusal (however implicit) to engage with questions of legitimacy, power or class is the best deployment of theoretical labour in the 21st century. The fact that such questions can only ever be answered through an open engagement with normative questions does not render them less important, as Werlen himself acknowledged in his somewhat inconclusive engagement with Peter Sedlacek's explicitly "normative" conceptualisation of social geography (Werlen, 1987, pp. 256-259).

In the absence of such an engagement, Werlen's theoretical labour encounters the risk of becoming a sophisticated selffulfilling prophecy that recognises everything, comprehends a lot and yet helps to critique nothing beyond the walls of theory. Lest, of course, the formulation of critique is deemed not to be part of the action-based context developed by Werlen, be it in the form of self-reflective capacities enacted by lay, everyday actors or by social geographers analysing the latter and their outcomes. It is here and finally that a more in-depth engagement of Werlen with the work of Jürgen Habermas might yet lead to future fruitful developments of what has already proven to be an impressive and genuinely fruitful engagement with theory and praxis alike. 


\section{References}

Bartels, D.: Zur wissenschaftstheoretischen Grundlegung einer Geographie des Menschen, Franz Steiner Verlag, Wiesbaden, 1968.

Best, U.: The invented periphery: constructing Europe in debates about "Anglo hegemony" in geography, Soc. Geogr., 4, 83-91, doi:10.5194/sg-4-83-2009, 2009.

Collinge, C: The différance between society and space: nested scales and the returns of spatial fetishism, Environ. Plann. D, 23, 189-206, 2005.

Erwägen Wissen Ethik, Volume 24, Heft 1, 2013.

Habermas, J.: Erkenntnis und Interesse, Frankfurt am Main, Suhrkamp. Translated into English by Jerermy Shapiro as Knowledge and human interests, Beacon Press, Boston 1971, 1968.

Hannah, M. and Strohmayer, U.: Ornamentalism. Geography, Language, and the Autonomy of the Subject in Structuration Theory, Environ. Plann. D., 9, 3, 309-327, 1991.

Meusburger, P.: Subjekt - Organisation - Region. Fragen an die subjektzentrierte Handlungstheorie, in: Handlungsorientierte Sozialgeographie. Benno Werlens Entwuf in kritischer Diskussion, Herausgeber: Meusburger, P., Stuttgart, Steiner, 95-132, 1999.
Minca, C.: (Im)mobile Geographies, Geogr. Helv., 68, 7-16, doi:10.5194/gh-68-7-2013, 2013.

Werlen, B.: Thesen zur handlungstheoretischen Neuorientierung sozialgeographischer Forschung, Geogr. Helv., 41, 67-76, doi:10.5194/gh-41-67-1986, 1986.

Werlen, B.: Gesellschaft, Handlung und Raum, Stuttgart, Steiner, 1987.

Werlen, B.: Society, Action and Space: An alternative human geography, Routledge, London, 1993.

Werlen, B.: Sozialgeographie alltäglicher Regionalisierungen. Band 1: Zur Ontologie von Gesellschaft und Raum, Stuttgart, Steiner, 1995.

Werlen, B.: Gesellschaft und Raum: Gesellschaftliche Raumverhältnisse. Grundlagen und Perspektiven einer sozialwissenschaftlichen Geographie, Erwägen Wissen Ethik, 24, 3-16, 2013a.

Werlen, B.: Replik: Weltbilder und Weltsichten. Von disziplinärer Repräsentation zu transdisziplinären Problemstellungen, Erwägen Wissen Ethik, 24, 76-91, 2013b. 